\title{
Factors Influencing College Students Recycling Attitudes and Behaviors
}

Author ORCID: https://orcid.org/0000-0002-6038-5120

Author Affiliation: John Omburo, PhD, Grand Canyon University, Phoenix, AZ

SC Classification Genre(s): Business, Education

Citation: Omburo, J. (2020). Factors influencing college students recycling attitudes and behaviors. Scholar Chatter, 1(1), 22-34, https://doi.org/10.47036/SC.1.1.22-34.2020

Creative Commons Attribution

(C) The Author. 2020. This is an open access publication through Scholar Chatter LLC.

\begin{abstract}
This study explored contextual factors that impact students recycling attitudes and behaviors on a community college campus in Texas, U.S.A. Previous studies revealed that it was unknown what community college students' attitudes and behaviors impact their recycling on a community college campus. Participants for the study had to be enrolled at the community college for studies at the time of data collection. An online questionnaire was used to collect self-administered data via SurveyMonkey, and the researcher conducted a face-to-face interview. Three constructs were utilized: attitudes, subjective norms, and perceived behavioral controls of the theory of planned behavior to explore what could be impacting students' active recycling participation on the community college campus. The population sample size was 13 community college students from Texas, U.S.A. A six-step thematic analysis was used to analyze data through the themes that emerged. The findings supported earlier research findings that people's attitudes are mainly dependent on the moral values and general norms of their society. The results and future research implications were discussed. The study revealed that most students had positive behaviors and recycled. Future researchers can conduct statistical analysis and extend the research to more colleges.
\end{abstract}

Keywords: Recycling benefits, recycling, recyclable materials, awareness, bins, and bin locations. 


\section{Introduction}

As the world's population continues to rise, so does the population of students in both lower and higher educational institutions. Increased population in institutions of learning comes with increased consumption resulting in the production of waste. Waste disposal can harm the environment, and so proper disposal programs should be practiced to avoid pollution. According to Hansen et al. (2008), environmental scholars have meticulously examined the relationships between pro-environmental attitudes and behavior and discovered that people with a proenvironmental attitude also engage in pro-environmental behaviors. Recycling is aimed at encouraging consumers to use resources conservatively and reused them when possible to minimize waste production (Hunsinger, 2017).

Similarly, Árnadóttir et al. (2019) researched the separation of waste in college cafeterias but failed to include determinants of intention, attitude, and subjective norms. Miller et al. (2016) also researched recycling at a university campus but did not include contextual factors such as sociocultural, educational, economic factors, and the U.S. Environmental Protection Agency regulations. This research study attempted to fill this gap by exploring the factors that impact students' attitudes and behaviors to recycle on a community college campus.

Environmental sustainability is a significant concern in every large organization, including universities and colleges. Large heterogeneous organizations such as universities do not have formal organizational structures to address sustainability issues. Therefore, successful recycling in universities and colleges is essential because the practice may influence students' attitudes and behaviors to adopt effective conservative practices that would save the world from environmental degradation (Weaver et al., 2015). It is, therefore, essential to mitigate pollution of the environment through recycling because landfilling with wastes such as plastics has got a severe impact on the environment (Klein, 2018). Recycling in higher learning institutions represents a large part of recycling programs globally and contributes enormously to community waste flow that promotes clean air and the environment (Ecker \& Kun, 2017). Therefore, successful recycling in universities and colleges is essential because the practice may influence students' present and lifelong attitudes toward adopting effective conservational practices that would save the world from environmental degradation (Klein, 2018). Thus, assessing and improving recycling programs in institutions of higher learning is a promising line of research within environmental sustainability.

\section{Advancing Scientific Knowledge and Significance of the Study}

Previous research studies confirmed that bin proximity influenced college students' behavior to recycle more. Still, the research relied only on the weight of the recyclable materials without considering other contextual barriers and facilitators that may affect students' recycling behavior. At the end of the earlier study, the researchers identified a need for further studies to explore other contextual variables that could affect students' recycling attitudes and behaviors.

According to Largo-Wight et al. (2012), an increase of bins without information on university campuses resulted in a significant increase in recycling. Despite an earlier assumption 
that a rise of bins without instructions would not increase recycling volume, but instead, there was a massive increase in recycling volume by $130 \%$ when indoor recycling bins were added. Therefore, the present study added to the body of knowledge by exploring whether students' socioeconomic, cultural, and educational background influences students' recycling behavior on university or college campuses. Recycling should promote the re-usage of materials in favor of a cleaner environment. The study also contributed to the existing theory and practice by providing useful insights into the attribution of perceived behavioral control on college students' recycling intentions. The construct perceived behavioral control refers to a person's perception of the ease or difficulty of performing the behavior of interest and varies across situations and actions (KaieChin, 2016).

\section{Literature Review}

With the world's population increase, there is also an imminent increase of student population in higher learning institutions that comes with higher consumption and an increase in waste production. A research study by Miller et al. (2016) explored bin proximity to learn about college students' recycling participation. The study revealed an increase in recycling when bins were placed at strategic places. However, the study did not investigate other contextual factors that could motivate college students to recycle on campus besides bin proximity. At the end of their research, Miller et al. (2016) reported that contextual variables such as attitudes and behaviors were not considered in their research study. Therefore, the researchers recommended further studies on those other contextual variables.

\section{Identification of the Gap}

According to the World Economic and Social Survey (2016), environmental sustainability is a significant concern in every large organization, including universities and colleges. Weaver et al. (2015) carried out a case study on recycling at a large university to explore how organizations' citizenship behavior develops. Large heterogeneous organizations such as universities do not have formal organizational structures to address sustainability issues. Therefore, successful recycling in universities and colleges is essential because it may influence students' attitudes to adopt effective conservative practices that would save the world from environmental degradation (Weaver et al., 2015). Positive actions to tackle environmental issues such as recycling and reduction of environmental pollution are one of the most critical steps taken seriously by the U.S. Environmental Protection Agency (Borella \& Borella, 2016).

\section{Theoretical and Conceptual Foundations}

The research study was based on the theory of planned behavior (TPB). According to Zaharie et al. (2014), a conceptual framework that includes either direct or moderating influential factors regarding recycling behavior shows that consumers' intention to recycle is deeply related to attitude, personal and social norms, and perceived behavioral control. The theory of planned behavior and the theory of reasoned action (TPB/TRA) helped explain several consumer moral decisions because the (TPB/TRA) builds on the connection between attitudes and intentions. The 
study was also based on a utilitarian model theory, which states that students' positive emotions towards recycling could overpower their negative consumption emotions by encouraging waste reduction and encourage reuse and recycling (Sun \& Trudel, 2017).

Although most consumers have become quite familiar with recycling, they are still far from adopting expected standard behavior. Recycling is also positively related to recycling intention, which is likely to increase when people feel that some important persons approve of their recycling behavior. People with predominantly independent self-construal and perceived social exclusion will exhibit an adverse effect on autonomous behaviors to maintain an intimate relationship with others.

Using the TPB, the study explored the attitudes and behaviors that impact students' recycling behavior. The study also attempted to investigate if perceived social exclusion could negatively affect students' attitudes towards recycling Zhou et al. (2017). Social exclusion is linked to people's need for a sense of belonging. Recycling attitude refers to people's positive or negative feelings towards recycling, which is crucial to recycling effectiveness (Chuang et al., 2016).

Drawing from the pro-environmental behavior framework of the TPB, the current research study explored the attitudes and behaviors affecting community college students' recycling on a community college campus. Ajzen (2005) also identified three categories of independent predictors of behavioral intention as an attitude towards the behavior, subjective norms, and perceived behavioral control with attitudes toward the behavior, meaning evaluation of behavior, or by an individual as good or bad.

The present study, therefore, examined students' sociocultural, educational, economic background, and U.S. Environmental Protection Agency regulations to identify contextual factors influencing their attitudes and behavior to recycle on campus. Self-administered questionnaires and individual student interviews were used to collect data that provided a more reliable analysis of students' recycling behavior and attitudes on a community college campus Balkaya and Bilgin, (2018). The self-administered questionnaires were used because they gave the respondents the freedom to answer and complete the questionnaires at their own pace and freedom from any influence of the researcher. It was also chosen because it allowed the researcher to reach many more respondents as possible. The analysis from different perspectives provided a better understanding of the research problem under investigation. Although the study by Miller et al. (2016) based on bin proximity revealed an increase in recycling on campus by students, the study was only interested in weight as a measure. The measure of weight alone did not allow for a fine-tuning that would consider other contextual variables. 


\section{Methodology}

\section{Qualitative Measures.}

Thirteen students were interviewed by the researcher on a one-on-one individual interview. In the second part of the questionnaires, 47 students responded to questions on SurveyMonkey. Data collected regarding students' recycling knowledge, socioeconomic, and sociocultural factors that may influence students' attitudes and behaviors towards recycling on campus. The researcher followed the six steps of thematic data analysis, as described by Braun and Clarke (2006) were used to analyze data. These six steps are: (a) familiarize oneself with data, (b) generate initial codes, (c) search for themes, (d) review themes, (e) define and name themes, and f) interpret themes. Once the data were collected from all sources, the raw data were organized and transcribed. The transcripts were then sent back to the participants for member checking, which enabled the researcher to verify the accuracy and worthiness of the data.

\section{Results}

While a plethora of research has been focusing on maintaining a sustainable and green environment through recycling, past studies had not been conducted to explore the impact of attitudes and behaviors of community college students regarding recycling on a community college campus. Despite the government and community college administration's efforts to increase recycling on community college campuses, all the students could still not follow the correct recycling procedures. Students freely shared their views on the benefits and side effects of recycling, and the choice of a descriptive design was, therefore, appropriate for the study (Nyvang et al., 2016).

The results of the study comprised four themes that emerged from the data: Theme 1: Students are not sure of what and where to recycle. Theme 2: Students recycle more when bins are clearly marked and have got time to do so when bins are available at convenient locations. Theme 3: Students recycle when they have the knowledge and believe that it is important, and theme 4: Students are not informed of the benefits of recycling or the impact on the environment and health. Data provided through these themes showed the attitudes, subjective norms, and perceived behavioral control facilitated recycling behavior or prevented such intentions to recycle.

\section{Descriptive Findings}

Descriptive data were collected using an online questionnaire via SurveyMonkey (see Table 1). A summary of the study participants' population and demographics came from a twoyear community college campus in Texas, U.S.A. The two-part questionnaires included a section to collect participants' demographic characteristics such as age, sex, ethnicity, and education level. The second part of the research included asking semi-structured questions to collect information regarding the socioeconomic, sociocultural, educational, and awareness of students that determine their attitudes and behaviors regarding recycling. 
Table 1. Demographics Profile of Research Participants

\begin{tabular}{lrr}
\hline \multicolumn{1}{c}{ Variable } & N & Percentage \\
\hline Gender, $n=33$ & & \\
Male & 15 & $54.45 \%$ \\
Female & 18 & $45.54 \%$ \\
Age, $n=33$ & & \\
18-24 years & 17 & $51.52 \%$ \\
25-34 years & 1 & $3.03 \%$ \\
35-44 years & 5 & $15.15 \%$ \\
45-54 years & 2 & $6.06 \%$ \\
55-64 years & 4 & $12.12 \%$ \\
$>$ 65 years & 2 & $6.06 \%$ \\
Ethnicity, $n=33$ & & \\
White or Caucasian & 7 & $21.21 \%$ \\
Black or African American & 14 & $42.42 \%$ \\
Hispanic or Latino & 11 & $33.33 \%$ \\
Asian or Asian American & 1 & $3.03 \%$ \\
American Indian or Alaskan Native & 0 & $0.00 \%$ \\
Native Hawaiian or Other Pacific Islanders & 0 & $0.00 \%$ \\
Another Race & 0 & $0.00 \%$ \\
Educational Level, $n=33$ & & \\
1st Year & 10 & $30.30 \%$ \\
2nd Year & 14 & $42.42 \%$ \\
3rd Year & 6 & $18.18 \%$ \\
4th Year & $3.09 \%$ \\
\hline
\end{tabular}

The majority of the participants were identified as Black or African American (14), followed by Hispanic and Latino (11), Caucasian (7), and Asian or Asian American (1). At the time of analysis, participants were in various stages of their community college experiences: 10 students were in their first year of college, 14 were second-year students, six participants were in the third year of college, whereas only three students were in the fourth year.

\section{Socioeconomic Factors}

Over $90 \%$ of the students interviewed confirmed that recycling could improve the community college's economic status and support the local and national economy (see Table 2). Almost $100 \%$ of the students interviewed agreed that recycling can enhance the community's economic well-being. At the same time, $100 \%$ agreed that recycling is beneficial to the environment, and over $90 \%$ of the students also s that recycling could save energy, and only $6 \%$ disagreed. 
Table 2. Socioeconomic Factors

\begin{tabular}{lrr}
\hline \multicolumn{1}{c}{ Socioeconomic Factors } & \multicolumn{1}{c}{ Yes } & \multicolumn{1}{c}{ No } \\
\hline Can recycling improve the economic status of the college? & $30(90.91 \%)$ & $3(3.33 \%)$ \\
Does recycling support the local and national economy? & $31(93.94 \%)$ & $2(6.06 \%)$ \\
Recycling costs and economic benefits. & $25(75.76 \%)$ & $8(24.24 \%)$ \\
Can recycling improve the economic status of the college? & $29(87.88 \%)$ & $4(12.12 \%)$ \\
Can recycling improve the economic well-being of the & $32(96.97 \%)$ & $1(3.03 \%)$ \\
community? & $31(93.94)$ & $2(6.06 \%)$ \\
Can recycling be beneficial in job creation of the community? & $33(100 \%)$ & $0(0.00 \%)$ \\
Economic benefits of recycling for the environment? & $31(93.94 \%)$ & $2(6.06 \%)$ \\
Can recycling save energy?
\end{tabular}

\section{Educational Knowledge and Awareness}

Students shared their knowledge about the U.S. Environmental Protection Agency, and only $61 \%$ knew about the U.S. Environmental Protection Agency, while about $40 \%$ were unaware (see Table 3). Eighty-four percent of the students who knew about the role of the U.S. Environmental Protection Agency agreed that the organization might help in environmental management while 15\% disagreed. One hundred percent of the students who participated in the study agreed that knowledge of recycling could improve recycling on campus. Eighty-two percent participated in recycling on the community college campus, and only about $64 \%$ consented finding recycle/trash bins close to each other. Thirty-six percent said that they did not always find trash/recycle bins close to each other all the time, and that is why they do not recycle sometimes.

Table 3. Educational Knowledge and Awareness of Participants

\begin{tabular}{lcc}
\hline \multicolumn{1}{c}{ Socioeconomic Factors } & Yes & No \\
\hline $\begin{array}{l}\text { Do you know about the U.S. U.S. Environmental Protection } \\
\text { Agency? }\end{array}$ & $20(60.61 \%)$ & $13(39.39 \%)$ \\
$\begin{array}{l}\text { Do you think the knowledge of U.S. Environmental } \\
\text { Protection Agency may help in environmental management? }\end{array}$ & $27(84.38 \%)$ & $5(15.63 \%)$ \\
$\begin{array}{l}\text { Do you think knowledge of recycling can improve recycling } \\
\text { on college campuses? }\end{array}$ & $33(100 \%)$ & $0(0.00 \%)$ \\
$\begin{array}{l}\text { Do you think recycling can help us in managing global } \\
\text { warming? }\end{array}$ & $29(87.88 \%)$ & $4(12.12 \%)$ \\
$\begin{array}{l}\text { Do you often recycle? } \\
\text { Do you always find recycle bins next to trash bins? }\end{array}$ & $27(81.82 \%)$ & $6(18.18 \%)$ \\
\hline
\end{tabular}




\section{Sociocultural Factors}

When sociocultural factors were considered regarding recycling on community college campuses, only $24 \%$ of the students shared that recycling was good for some people, while over $70 \%$ disagreed (see Table 4). During further interviews, almost $100 \%$ of the students agreed that recycling creates jobs, conserve the environment, and saves resources. Only 63\%were concerned when people do not recycle. On further interviews, $96 \%$ of the students said that recycling could reduce the amount of waste going into the landfill, and 100\% agreed that recycling could save and protect the environment.

Table 4. Sociocultural Factors

\begin{tabular}{lrr}
\hline \multicolumn{1}{c}{ Sociocultural Factors } & \multicolumn{1}{c}{ Yes } & \multicolumn{1}{c}{ No } \\
\hline Do you think recycling is just good for some people? & $8(24.24 \%)$ & $25(75.76 \%)$ \\
Do you think recycling can create jobs for the community? & $32(96.97 \%)$ & $1(3.03 \%)$ \\
$\begin{array}{l}\text { Do you believe that recycling on college campuses can help } \\
\text { conserve the environment? }\end{array}$ & $31(93.94 \%)$ & $2(6.06 \%)$ \\
Are you concerned when people do not recycle on campus? & $21(63.64 \%)$ & $12(36.36 \%)$ \\
Do you think that recycling is good for businesses only? & $2(6.06 \%)$ & $31(93.94 \%)$ \\
Do you believe that recycling can save resources? & $32(96.97 \%)$ & $1(3.03 \%)$ \\
Do you believe recycling saves energy? & $29(87.88 \%)$ & $4(12.12 \%)$ \\
Do you think recycling can save and protect the & $33(100 \%)$ & $0(0.00 \%)$ \\
environment? & $32(96.97 \%)$ & $1(3.03 \%)$ \\
Do you believe recycling can help to reduce the amount of & & \\
waste going into landfills? & $3(9.09 \%)$ & $30(90.91 \%)$ \\
Do you just recycle because other students do the same? & $4(12.12 \%)$ & $29(87.88 \%)$ \\
Do you not recycle because other students do not? & $25(78.13 \%)$ & $7(21.88 \%)$ \\
Are recycle bins located in accessible positions easily &
\end{tabular}
noticeable to students?

Even though $100 \%$ of the students said that recycling could reduce the amount of waste going into landfills, $6 \%$ of the students still said that recycling was only good for businesses. Over $90 \%$ of the students said that they recycle on their own without other students' influence. Recycling was also influenced by the availability of bins in the right places. Therefore, over $78 \%$ shared that they only recycled when bins were placed in accessible and convenient locations.

\section{Discussion and Summary of the Study}

This article has been based on a research study exploring contextual factors impacting students recycling attitudes and behaviors on the community college campus. Before the study, it was unknown what influenced community college students' attitudes and behaviors regarding recycling on a community college campus. The research discovered that students responded to 
recycling practices based on prior knowledge they had from pre-primary, high schools, and their families. Unfortunately, even though students who had known the benefits of recycling did not recycle on the community college campus because they were not reminded through continuing education or promotion campaigns. Students shared that they were only reminded to work hard on their academic work at the community college, and no information was shared with them about the environment. The findings were also consistent with (Ahmad et al., 2016) research findings that revealed knowledge and awareness of the surrounding recycling practices influences students to recycle. Data collected from students revealed that knowledge about the benefits of recycling influenced students' recycling behavior.

The students who had positive attitudes and behaviors about the environment participated in recycling, and the study revealed that they had prior knowledge and awareness of recycling. Environmental education is the ability to understand and evaluate habitat issues that impact society and the environment. Therefore, environmental, or ecological consciousness is the ability to decipher and evaluate the impact of the environment on society and the habitat. The students who did not recycle were not motivated, careless, and lacked awareness of recyclables and nonrecyclable materials.

The study results also provided evidence that students with positive attitudes towards the environment recycled all different kinds of recyclable materials. The students also shared that they separated the food and other solid waste because they knew that mixing recyclable and waste products were not good for the environment. Failure to separate recyclable materials from trash at the point of disposal of unused materials allows toxic and non-biodegradable materials to end up in landfills. None-biodegradable materials cannot decompose or dissolve for many years.

Students shared that they only recycled when it was convenient for them, and when they had time. Students who did not recycle did not know of the benefits of recycling. Demographic data also revealed that students' attitudes and behavior are affected by factors such as age, education, and income. The study findings revealed that most of the students who knew about recycling recycled both at home and the community college; however, lack of awareness and motivation affected few students' recycling behaviors. Environmental knowledge also played a role in students' attitudes and behavior regarding recycling.

Data collected also revealed that students' behaviors were influenced by knowledge and awareness of the benefits and consequences of not recycling. Students also believed that recycling awareness campaigns could encourage students to recycle. The proper labeling of bins also encouraged students to recycle. Data sources also revealed that some students who did not recycle were not quite sure of what to recycle or not to recycle. Finally, the lack of information and time were also prominent factors that influenced students' recycling attitudes and behaviors.

\section{Recommendations}

A thorough review of existing literature identified a further need to explore community college students' attitudes and behaviors regarding recycling on a community college campus. 
Over the years, there have been efforts made by the local government and political organizations to increase awareness and benefits of recycling and initiate recycling programs publicly. However, little was known about students' attitudes and behaviors impacting on their recycling programs in community colleges (Árnadóttir et al., 2019; Miller et al., 2016)

\section{Future Research}

Future research should replicate the study by broadening the geographic locations and sample population to include more students from other community colleges in different geographic locations throughout the United States. The study focused on students from only one two-year community college. Future research should include four-year colleges to expand the sample and have other students, such as elementary, high school, and postgraduate students, to see if there will be a change in those students' behaviors and attitudes towards recycling on campuses. Future research should replicate the study by using a quantitative methodology to embrace a larger sample size that will allow generalization of the results.

Students who were not enrolled in classes and aware of the recycling process were left out of the study. Future studies should include those students to see if recycling campaigns can influence their recycling attitudes and behaviors. All students from the community college were covered in the study, and future research should include teachers and administrators to see if their views on the recycling process in college would make a difference and seek recommendations to increase the recycling by students in the community college.

It was also revealed that bin location and communication regarding the types of bins influenced students' recycling attitudes and behaviors. Future research should be conducted in colleges where the bin locations are adequate and stickers placed on the bins to see if those students' recycling behaviors are significantly better than in colleges without sufficient bins. Future research can use an observational measure to observe actual recycling behaviors of students to collect real data on recycling.

\section{Conclusions}

Students' responses were able to help in answering the two research questions: What are the attitudes of community college students regarding recycling on a community college campus? And what are the behaviors of community college students regarding recycling on a community college campus? The conclusions derived from the data analysis had theoretical support and foundation from empirical data leading to the findings in the current study. Environmental protection has been recognized as a core to public health in the U.S.A. and around the world. As the population increases, so does consumption; consequently, climate change occurs due to pollution because pollution starts with individuals when recyclable materials are not separated at source (Motesharrei et al., 2016). Large heterogeneous organizations such as universities do not have formal organizational structures to address sustainability issues. Therefore, successful recycling in universities and colleges is essential because that may influence students' attitudes and behaviors to adopt effective conservative practices that would save the world from environmental degradation (Weaver et al., 2015). 
The study showed that students with a positive attitude towards the environment and recycled separated recyclable from trash materials (Kim, 2015). The students who were not inclined to the importance of recycling were also not convinced that recycling was cost-saving and had economic benefits. The study results also supported the construct of behavioral intentions by showing that perceived behavioral control facilitated recycling behavior or prevented such intentions to recycle. Lack of proper communication, proper labeling, and awareness among students regarding recycling campaigns in the community college contributed to the failure of students to recycle effectively.

\section{Funding}

The research for this article was funded solely by the author.

\section{Acknowledgments}

The author thanks Dr. S. Ydoyaga for facilitating and assisting with permission to collect data from the two-year community college. Special thanks also go to my dissertation chair, Dr. Linski, and his committee members to complete the study. Further appreciation is extended to Prof. Okello together with Mr. Mike and Mr. Royce for their support during data collection.

\section{References}

Ahmad, M. S., Bazmi, A. A., Bhutto, A. W., Shahzadi, K., \& Bukhari, N. (2016). Students' responses to improve environmental sustainability through recycling: Quantitatively improving qualitative model. Applied Research in Quality of Life, 11(1), 253-270. https://doi.org/10.1007/s11482-014-9366-7

Ajzen, I. (2005). Attitudes, personality and behavior ( $2^{\text {nd }}$ ed.). Maidenhead: Open University Press

Árnadóttir, Á., Kok, G., Gils, S. V., \& Hoor, G. T. (2019). Waste separation in cafeterias: A study among university students in the Netherlands. International Journal of Environmental Research and Public Health, 16(1), 93. https://doi.org/10.3390/ijerph16010093

Balkaya, N., \& Bilgin, A. (2018). University students' recycling behavior and attitudes toward the disposal of solid wastes. Recycling and Reuse Approaches for Better Sustainability Environmental Science and Engineering, 39-52. https://doi.org/10.1007/978-3-31995888-0_4

Borella, I. L., \& Borella, M. R. (2016). Environmental impact and sustainable development: An analysis in the context of standards ISO 9001, ISO 14001, and OHSAS 18001. Environmental Quality Management, 25(3), 67-83. https://doi.org/10.1002/tqem.21460 
Braun, V., \& Clarke, V. (2006). Using thematic analysis in psychology. Qualitative research in psychology, 3(2), 77-101.Chuang, Y., Xie, X., \& Liu, C. (2016). Interdependent orientations increase pro-environmental preferences when facing self-interest conflicts: The mediating role of self-control. Journal of Environmental Psychology, 46, 96-105. https://doi.org/10.1016/j.jenvp.2016.04.001

Chuang, Y., Xie, X., \& Liu, C. (2016). Interdependent orientations increase pro-environmental preferences when facing self-interest conflicts: The mediating role of self-control. Journal of Environmental Psychology, 46, 96-105. https://doi.org/10.1016/j.jenvp.2016.04.001

Ecker, J. R., \& Kun, Y. (2017). Waste management in campus dining--reformatting "Recycle mania” at Central Michigan University. Business Management Dynamics, 7(1), 1. http://bmdynamics.com/issue_pdf/bmd110923-01-11.pdf

Hansen, L. T., McMellen, C., Olson, L., Kaplowitz, M., Kerr, J., \& Thorp, L. (2008). Recycling attitudes and behaviors on a college campus: Use of qualitative methodology in a mixedmethods study. Journal of Ethnographic \& Qualitative Research, 2(3), 173-182.

Hunsinger, M. (2017). Interpreting appropriate and necessary reasonably under the clean air act: Michigan v. environmental protection agency. Ecology Law Quarterly, 44(2), 535-543. doi: 10.15779/Z38QZ22G8H

Kaie-Chin, C. (2016). Exploring customers' post-dining behavioral intentions toward green restaurants: An application of theory of planned behavior. International Journal of Organizational Innovation, 9(1), 119-134.

Kim, H. (2015). The effect of a climate change monitoring program on students' knowledge and perceptions of steam education in Korea. Eurasia Journal of Mathematics, Science and Technology Education, 11 (6), 1321-1338. https://doi.org/10.12973/eurasia.2015.1390a

Klein, E. (2018). Can a sustainable context predict recycling? Sustainable design impacts on proenvironmental behaviors and perceptions. Logos: A Journal of Undergraduate Research, 11, 129-150.

Largo-Wight, E., Bian, H., \& Lange, L. (2012). An empirical test of an expanded version of theory of planned behavior in predicting recycling behavior on campus. American Journal of Health Education, 43(2), 66-73. https://doi.org/10.1080/19325037.2012.10599221

Miller, N. N., Meindl, J. N., \& Caradine, M. (2016). The Effects of bin proximity and visual prompts on recycling in a university building. Behavior \& Social Issues, 25(1), 4-10. https://doi.org/10.5210/bsi.v25i0.6141 
Motesharrei, S., Rivas, J., Kalnay, E., Asrar, G. R., Busalacchi, A. J., Cahalan, R. F., "Cane, M. A., Colwell, R. R., Feng, K., Franklin, R. S., Hubacek, K., Miralles-Wilhelm, F., Miyoshi, T., Ruth, M., Sagdeev, R., Shirmohammadi, A., Shukla, J., Srebric, J., Yakovenko, V. M., \& Zeng, N. (2016). Modeling sustainability: Population, inequality, consumption, and bidirectional coupling of the earth and human systems. National Science Review, 3(4), 470-494. https://doi.org/10.1093/nsr/nww081

Nyvang, J., Hedstrom, M., \& Gleissman, S. (2016). It is not just a knee, but a whole life: A qualitative descriptive study on patients' experiences of living with knee osteoarthritis and their expectations for knee arthroplasty. International Journal of Qualitative Studies on Health \& Well-Being, 11, 1-9. https://doi.org/10.3402/qhw.v11.30193

Sun, M., \& Trudel, R. (2017). The effect of recycling versus trashing on consumption: Theory and experimental evidence. Journal of Marketing Research (JMR), 54(2), 293. https://doi.org/10.1509/jmr.15.0574

Weaver, S. T., Ellen, P. S., \& Mathiassen, L. (2015). Contextualist inquiry into organizational citizenship: Promoting recycling across heterogeneous organizational actors. Journal of Business Ethics, 2, 413. https://doi.org/10.1007/s10551-014-2165-0

World Economic and Social Survey. (2016) Climate change resilience for sustainable development. (2016). World Economic and Social Survey (WESS),1-19. https://doi.org/10.18356/6bf07ffd-en

Zaharie, M. M., Pop, C., \& Romonti-Maniu, A. (2014). How moderating effects predict recycling behavior? An examination of situational factors and satisfaction with the local council. Marketing from Information to Decision, 1(7), 201-211.

Zhou, N., Huang, J., \& Wei, T. (2017). Interactive effects of perceived social exclusion and selfconstrual on recycling behavior. Social Behavior and Personality, 45(3), 491-503. https://doi.org/10.2224/sbp.6146 